successfully demonstrated in frozen sections of rat livers which were substituted in acetone containing $0.02-0.04 \%$ osmium tetroxide.

Further studies on this subject is being in progress.

\title{
Studies on Freeze-Substitution Method in Histochemistry (II)
}

\author{
Akitoshi Sugrmoto, Toshio Yagi, Kinji Okamoto, Haruo Hiraoka, \\ Kazuo Sakamoto and Fusazo TAguchi \\ Dept. of Oral Pathl., Osaka Univ. Dent. Sch., Osaka, Japan
}

\begin{abstract}
Freeze-substitution method has been generally recognized as a convenient and useful one in histochemistry, since Lison (1953) ${ }^{11}$. The authors reported previously that the substitution medium containing such fixatives as sublimatum etc. showed some excellent results for tissue preservation ${ }^{2)}$. In the present study, some methods which treat the freeze-substitute materials at relatively low temperature were investigated to remove any fault of heating during embedding in paraffin.
\end{abstract}

\section{Materials and Methods}

Kidney and other major organs of normal rats and mice were fixed in cold neutral $10 \%$ formalin, alcohol or acetone $\left(0 \sim 4^{\circ} \mathrm{C}\right)$ for one hour respectively, or in chilled iso-pentane (by liquid nitrogen, about $-165^{\circ} \mathrm{C}$ ) for several minutes. After fixation, tissue sections were cut according to the following procedures. 1) Ordinary freezing method by $\mathrm{CO}_{2}$. 2) Xylol-paraffin method after dehydration through alcohol and xylol, the slices were embedded in xylolparaffin (m. p. $37^{\circ} \mathrm{C}$ ) and cut in a cryostat (about $0 \sim 10^{\circ} \mathrm{C}$ ). 3) PVA method the slice fixed in formalin, alcohol or acetone and freeze-substituted slices which were brought to water through degraded cold alcohol were immersed and embedded in polyvinyl alcohol (PVA).

Preliminary Examination on PVA Method: Since utilization of PVA as a histological embedding medium was introduced first by Lubkin \& Carsten $\left.(1942,1944)^{3,4}\right)$ PVA method of embedding has been tried in histochemistry by several authors $\mathrm{s}^{5-8)}$, and the most detailed technic and results were reported by Feder $(1962)^{9}$.

The authors tried to find out a reproducible standard procedure using some commercial PVA. The PVA samples tested were six kinds of "Gohsenol" which were offered by favour of Nihon Gōsei Kagaku Kôgyô Co. (products NH-20, \#58, NH-26, NL-05, GH-20, and GH-17). Among these products, tested as 10 
and $20 \%$ solutions, dense solutions $(20 \%)$ of $\mathrm{NH}-20, \# 58$, and $\mathrm{NH}-26$ were found to be useful for embedding. Glycerol $(0 \sim 30 \%)$, formalin $(5 \sim 10 \%)$, boric acid $(0.5 \sim 10 \%)$, borax $(0.5 \sim 10 \%)$, and Carbowax $(1 \sim 30 \%)$ were tested as additional agents. The following solutions were chosen as useful immersing or embedding media for standard usage.

Solution I : 15\% PVA (NH-20) and 15\% glycerol in water (for immersing).

Solution II : 17 20\% PVA and 17 20\% glycerol in water (for immersing and/or for embedding).

Solution III : 17\% $\dot{0}$ PVA, $17 \%$ glycerol, and 1\% Carbowax in water (for embedding).

Each solution was stirred on a water bath until it became clear, and then kept in a incubator at $60^{\circ} \mathrm{C}$ until use. Fixed or freeze-substituted tissue slices were immersed in Solution I or II for a day or two, and embedded in Solutions II or III at room temperature. The embedded tissue blocks were dried in a desiccator with $\mathrm{CaCl}_{2}$ at $4{ }^{\circ} \mathrm{C}$ in an ice box or at room temperature for $10 \sim 14$ days. Some blocks were dehydrated in $90 \sim 100 \%$ alcohol for a few days. Sections were cut at $4 \sim 10 \mu$, and mounted on glass slides after floating on water or alcohol $(70 \%)$, with or without albumin.

Staining Reactions: Histochemical procedures applied were as follows: 1) Alkaline phosphatase (ALP-ase) coupling azo dye method ${ }^{10)}$ (substrate : sodium $\alpha$-naphthyl phosphate, coupler: Fast blue B; at $\mathrm{pH} 9.2$ with $\mathrm{KCl}$-boric acid$\mathrm{NaOH}$ buffer, at room temperature). 2) Acid phosphatase (ACP-ase) coupling azo dye method $^{10)}$ (substrate: the same as ALP-ase, coupler: Fast Garnet $\mathrm{GBC}$; at $\mathrm{pH} 4.8$ with acetate buffer, at room temperature). 3) Non-specific esterase coupling azo dye method ${ }^{11}$ (substrate: $\alpha$-naphthyl acetate, coupler: Fast blue $\mathrm{B}$; at $\mathrm{pH} 8.1$ with $0.2 \mathrm{M} \mathrm{Na}_{2} \mathrm{HPO}_{4}$, at room temperature). 4) G-Nadi oxidase... Gräff's method ${ }^{12)}(0.1 \% \alpha$-naphthol, $0.12 \%$ dimethyl-p-phenylenediamine, and

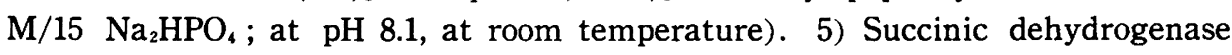
(SDH-ase) $\cdots$ Nachlas et al's Nitro-BT method ${ }^{13)}$ ( $0.2 \mathrm{M}$ sodium succinate, buffer

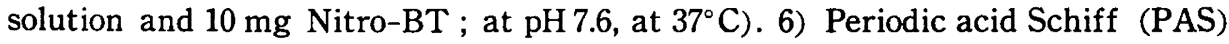
reaction Hotchkiss $\cdots$ method $^{14)}$. 7) Sudan black B and Sudan III stain ${ }^{15)}$. 8) Ordinary HE and Mallory-Heidenhain stains for morphological observation.

\section{Results and Discussion}

The results of enzymatic reactions are summerized in Table I.

Frozen Section: Although unfixed frozen sections retain high enzymatic activity, they cannot be recommended because of serious diffusion artifacts. Fixation in cold neutral formalin, alcohol, or acetone at $0 \sim 4^{\circ} \mathrm{C}$ was recommanded by Seligman et al $(1951)^{16}$ ) and others, but considerable diffusion and loss or inactivation of enzymes have been noted after fixation or washing in water, especially in case of labile and soluble enzymes ${ }^{17}$. Even sectioning by cryostat cannot avoid all of these deleterious effects ${ }^{15}$.

In the present study, all of the enzymatic reactions tested showed some moderate activities, but the reactions were considerably irregular as seen in Table I. That is, esterase and SDH-ase were fairly preserved after cold acetone 
Table 1. Results of the Enzymatic reactions After Various Fixations \& Embeddings (Rat Kidney)

\begin{tabular}{|c|c|c|c|c|c|c|}
\hline $\begin{array}{l}\text { Embedding or } \\
\text { Sectioning } \\
\text { Methods }\end{array}$ & Fixatives & ALP-ase & $\mathrm{ACP}$-ase & Esterase & Oxidase & SDH-ase \\
\hline \multirow{3}{*}{ Frozen Section } & Formalin & (H) & $(+)$ & $H$ & $H$ & + \\
\hline & Alcohol & $(H)$ & $(+)$ & + & + & $(H)$ \\
\hline & Acetone & $(H)$ & $(+)$ & H & + & $\mathrm{H}$ \\
\hline \multirow{4}{*}{$\begin{array}{c}\text { Xylol-Paraffin } \\
\text { Method }\end{array}$} & Formalin & $\mathrm{H}$ & $(+)$ & $H$ & \pm & - \\
\hline & Alcohol & $H$ & $(+)$ & $H$ & \pm & - \\
\hline & Acetone & $\mathrm{H}$ & $(t)$ & $H$ & \pm & - \\
\hline & Freeze-Substitution & m & $(H)$ & $H$ & \pm & - \\
\hline \multirow{4}{*}{$\begin{array}{c}\text { PVA embedding } \\
\text { Method }\end{array}$} & Formalin & $(H)$ & $(+)$ & tt & $(H)$ & $(+)$ \\
\hline & Alcohol & $(H)$ & $(+)$ & + & $(+)$ & $(+)$ \\
\hline & Acetone & m & $(+)$ & $H$ & $(+)$ & $(+)$ \\
\hline & Freeze-Substitution & $\mathrm{H}$ & $H$ & $\mathrm{H}$ & $H$ & $H$ \\
\hline
\end{tabular}

Notes: $\#$ intense, $\#$ moderate, + weak, \pm trace, - negative reaction;

( ) shows a labile and/or irregular reaction.

fixation, while ALP-ase and ACP-ase reactions showed moderate diffusion artifacts even after fixation.

Xylol-Paraffin Method: To avoid an inactivating effect of heating during embedding, xylol-paraffin mixture (m.p. abut $37^{\circ} \mathrm{C}$ ) was employed as embedding medium. Sections were cut at about $10 \mu$ in a cryostat at $5^{\circ} \mathrm{C}$ or so, and mounted on slides through floating on cold alcohol or acetone. In these sections, ALP-ase retained a high activity and exhibited little diffusion, and esterase reaction was fairly good. But $\mathrm{ACP}$-ase was moderately lost or inactivated, and then oxidase and SDH-ase reactions were trace or negligible, as seen in ordinary fixed or embedded sections.

PVA Method: Comparing to the frozen and xylol-paraffin sections, the PVA-mbedded materials through freeze-substitution method exhibited generally higher and more constant enzymatic activities, except for ACP-ase.

1) ALP-ase reaction : Since Takamatsu $(1939)^{18)}$ and Gomori (1939) ${ }^{19}$ ) originally demonstrated this enzyme in acetone- and alcohol-fixed tissue sections, many modifications have been tried on fixation and sectioning, including fresh freezing, cryostat, and freeze-drying methods. Previously, the authors ${ }^{(0)}$ reported that freeze-substitution method followed by a coupling azo dye method showed high activity and excellent localization of this enzyme. In PVA-embedded sections, activity and localization of ALP-ase were as good as in freeze-substituted paraffin sections, and they seemed to be comparable favourably to those in freeze-dried sections ${ }^{20)}$.

2) ACP-ase reaction : As this enzyme is more labile and its reaction has less specificity and less localization than ALP-ase reaction, its distribution and biological role in the tissue are not clear yet. As in recent years, Burstone et $\mathrm{al}^{21,22)}$ have developed some new method using naphthyl AS phosphate and new coupler, they will be brought to light before long. Novikoff et al (1961) ${ }^{7}$ described, in reference to the report of Holt et al $(1959)^{23)}$, that PVA embedding 


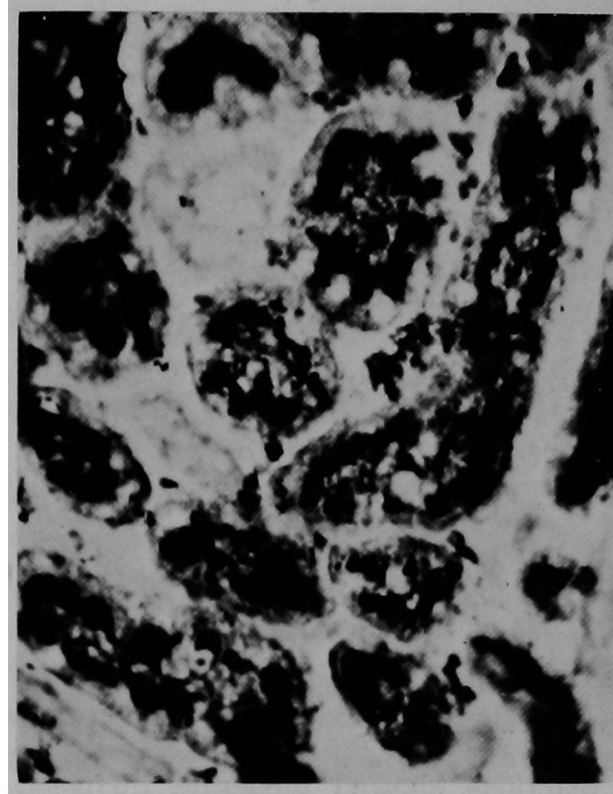

Fig. 1. Freeze-substituted xylol-paraffin section of rat kidney. ALP-ase reaction. $\times 1200$. High enzymatic activity is localized in supranuclear or apical portion of the cytoplasm. The nucleus is not stained.

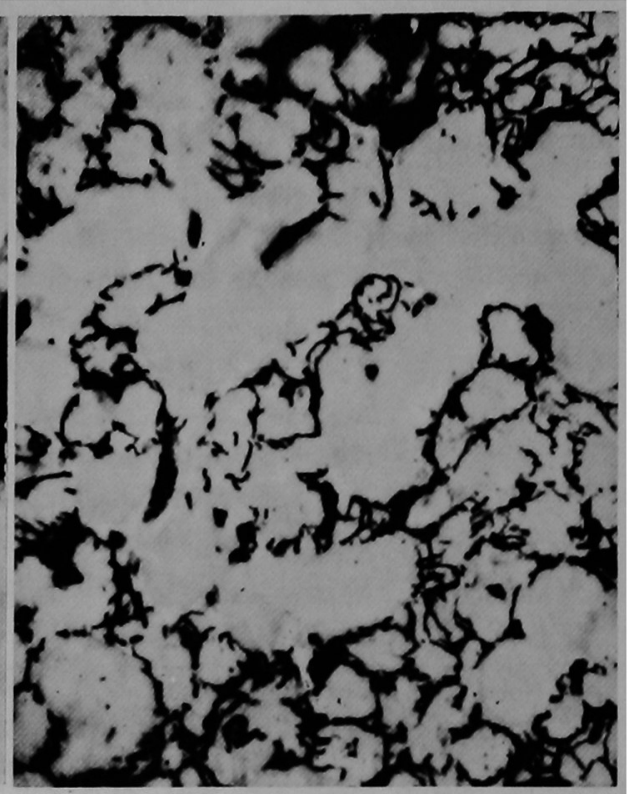

Fig. 2. Freeze-substituted xylol-paraffin section of rat submaxillary gland. ALPase reaction. $\times 600$. The reaction is 10 calized in the myoepithelial cells and capillaries. The parenchymatous cells are negative thoroughly.

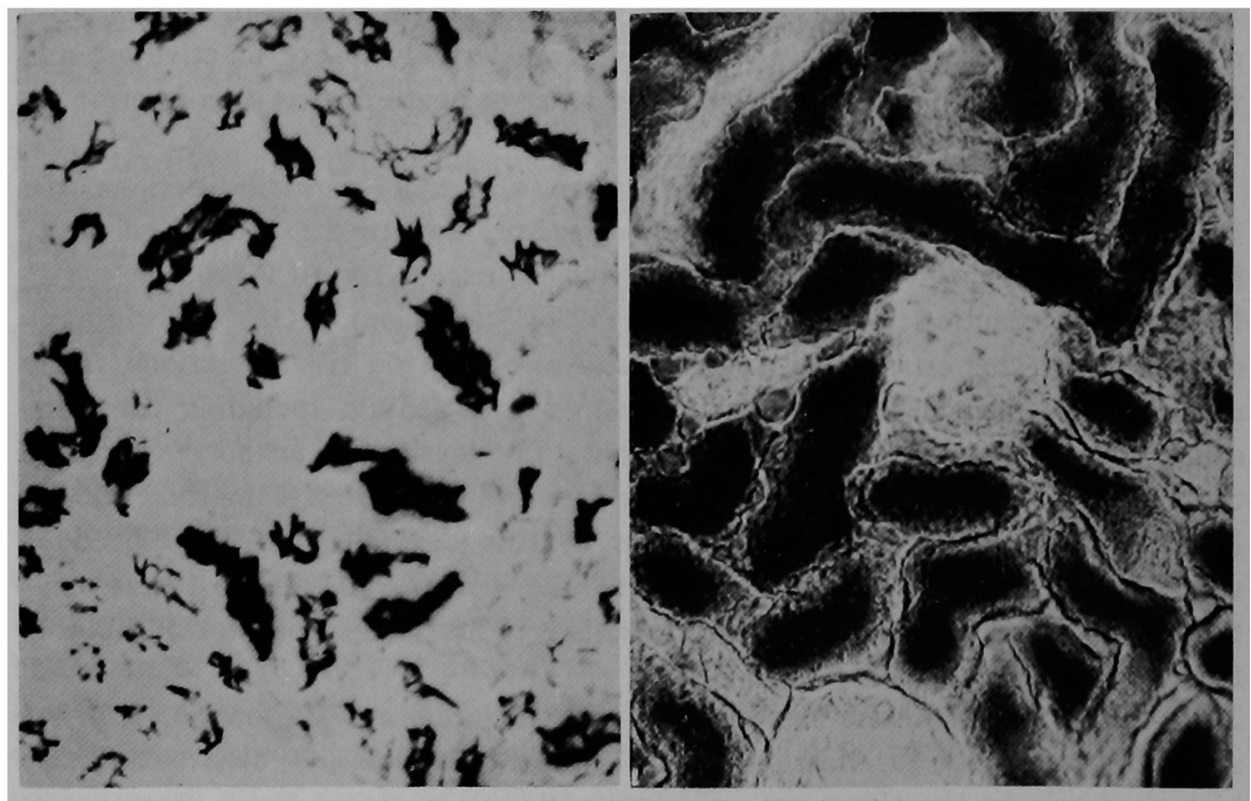

Fig. 3. Freeze-substituted PVA section of rat kidney. ALP-ase reaction. $\times 600$. Distribution of the reaction is similar to that in Fig. 1, while somewhat less intense and more sharp.

Fig. 4. Freeze-substituted PVA section of rat kidney. ACP-ase reaction. $\times 1200$. Proximal convoluted tubules exhibit high enzymatic activity, but considerable diffusion artifact is seen. 


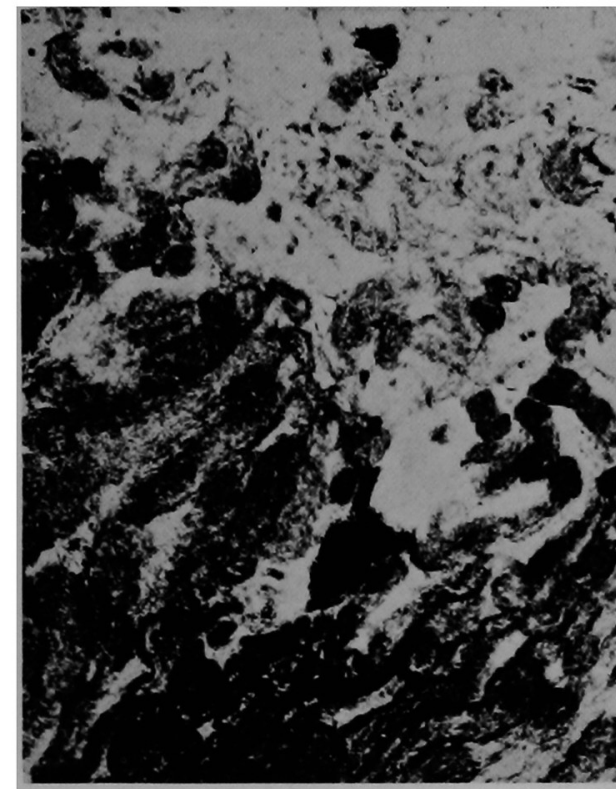

Fig. 5. Freeze-substituted PVA section of rat kidney. Oxidase reaction. $\times 300$. G-Nadi oxidase reaction is rather more intense in the medullary area than in the cortex.

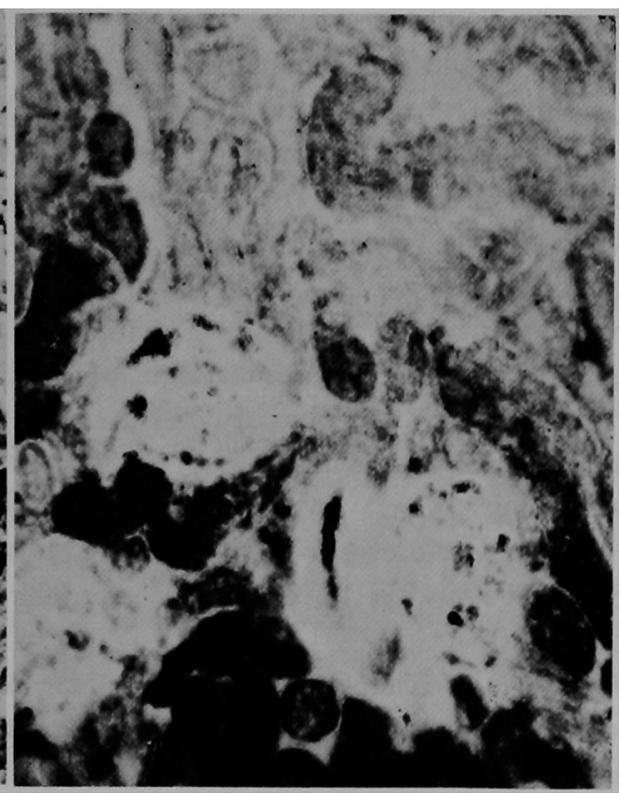

Fig. 6. Higher magnification of Fig. 5 . $\times 800$. The enzymatic reaction is localized in the cytoplasm of the tubular epithelium and in the polynuclear leuco. cytes in the glomeruli.

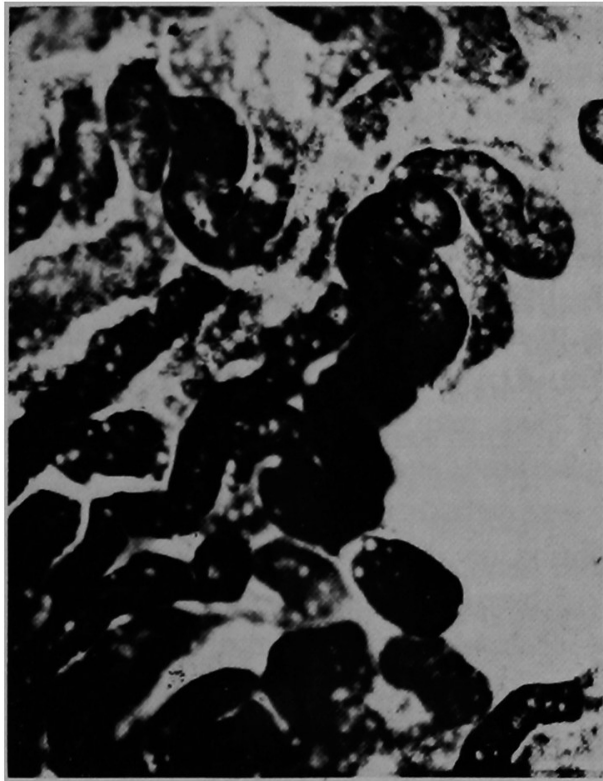

Fig. 7. Cold acetone-fixed frozen section of rat kidney. $\mathrm{SDH}$-ase reaction. $\times 600$. Intense reaction is seen in the tubular cytoplasm in the renal cortex, but it is ill-localized and coarsely granular in form.

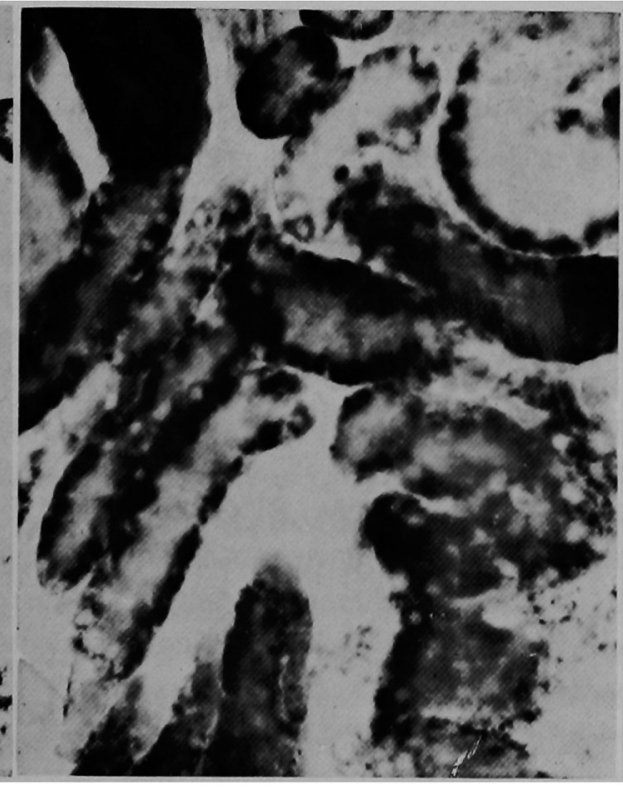

Fig. 8. Freeze-substituted PVA section of rat kidney. SDH-ase reaction. $\times 1200$. The reaction is well-localized and finely granular; excellent in the infranuclear cytoplasmic portion. The nucleus is negative. 
appeared to reduce the damage of the ACP-ase activity and that it was readily demonstrable in PVA blocks stored for 8 months.

In the present study, however, ACP-ase reaction was always labile and irregular at least by the method employed here, although the freeze-substituted PVA sections showed somewhat intense reaction.

3) Esterase reaction: This enzyme was fairly stable and demonstrated easily in most of sections prepared by the procedures mentioned above and with a coupling azo dye method. Distribution and localization of the reaction revealed generally little diffusion artifact and little differences from the previous reports carried on by the similar method. ${ }^{11,24}$ In this study, freeze-substituted PVA sections showed some what higher activity than in xylol-paraffin sections, also.

Wachstein et al $(1961)^{8)}$ has reported also that in formol-fixed PVA sections esterase reaction appeared in granular state similar to those in freeze-dried sections.

4) G-Nadi oxidase reaction: Oxidase has been thought one of the most labile enzyme, so that unfixed frozen sections were recommended for the reaction since Gräff (1911). ${ }^{12)}$ Recently, Burstone $(1959,1960)^{25,26)}$ demonstrated tissue oxidase with new reagents in raw frozen sections, and pointed out that brief fixation $(2 \sim 4 \mathrm{hrs})$ in cold neutral formalin resulted in marked inhibition of the enzyme, and also paraffin embedded tissues including frozen-dried material exhibited no activity, while unembedded pieces of frozen-dried tissues were highly active.

Nadi oxdase reactions, in the present study, were seen in fixed frozen sections and freeze-substituted PVA sections. The activities, however, were considerably less intense than those reported by Burstone, presumably due to loss or inactivation and partly due to the technical difference employed.

5) SDH-ase reaction: The enzymes, which are demonstrable with reduction of tetrazolium salts, has been studied in fresh frozen sections, as they are labile and easily inactivated. In recent time, Becker et al $(1960)^{5)}$ demonstrated DPNH- and TPNH- tetrazolium reductases in the PVA sections of the rat brain fixed in cold formol-calcium, and ATP-ase, ADP-ase, and ACP-ase also. More recently, Birns \& Masek $\left.(1961)^{6}\right)$ reported that many hydrolytic and oxidative enzymes including dehydrogenase, phosphatases, and aminopeptidases can be demonstrable in the PVA sections of freeze-substituted rat liver and renal cortex. But they gave no detailed description on the finding in PVA sections. 6) Other histochemical reactions : Most of histochemical reactions other than enzymes, for example, staining reactions for lipids, proteins, and minerals can be applied to PVA sections, as partly reported by Lubkin \& Carsten (1944) ${ }^{4}$ ) and Feder (1962).9) But PAS reaction is not suitable because of PVA itself, besides diffusion of glycogen and mucoid according to our results.

\section{References}

1) Lison, L. (1953) : Histochimie et Cytochimie Animales. Principls et Méthodes. 2. éd. Gauthier-Villares, Pais. 2) Sugimoto, A. \& Yagi, T. (1961) : Tr. Soc. Path. Jap. 50: 
193. 3) Lubkin, V. and Carsten, M. (1942): Science 95: 363. 4) Lubkin, V. and Carsten, M. (1944) : Arch. Pat. 38 ; $229 . \quad$ 5) Becker, N. H., Goldfischer, S., Shin, W. Y., and Novikoff, A. B. (1960) : J. Biophys. Biochem. Cytol. 8; 649. 6) Birns, M. and Masek, B. (1961) : J. Hisochem. Cytochem. 9; 204.7 7) Novikoff, A. B., Drucker, J,. Shin, W.-Y., and Goldfischer, S. (1961) : J. Histochem. Cytochem. 9;434. 8) Wachstein, M., Meisel, E., and Falcon, C. (1961) : J. Histochem. Cytochem. 9; $325 . \quad 9)$ Feder, N. (1962) : J. Histochem. Cytochem. $10 ; 341$. 10) Sugimoto, A. et al (1957) : Tr. Soc. Path. Jap. 46 ; 137. 11) Gomori, G. (1952) : Internatl. Rev. Cytol. 1 ; 323 . 12) Gräff, S. (1922) : Zbl. Path. 32 ; $337 . \quad 13)$ Nachlas, M. M. et al (1957) : J. Histochem. Cytochem. 5 ; 420. 14) Hotchkiss, R. D. (1946) : Arch. Biochem. 26 ; 131 . 15) Pearse, A. G. E. (1960): Histochemistry. Theoretical and Applied. J. \& A. Churchill, Ltd., London, 2nd ed. 16) Seligman, A. M., Chauncey, H. H., and Nachlas, M. M. (1951) : Stain Technol. 26 ; 19. 17) Gomori, G. and Chessick, R. D. (1953) : J. Cell \& Comp. Physiol. 41 ; 51. 18) Takamatsu, H. (1939) : Tr. Soc. Path. Jap. 29 ; $492 . \quad 19)$ Gomori, G. (1939) : Proc. Soc. Exp. Biol. \& Med. 42 ; 23. 20) Yasuda, T. (1957) : Tr. Soc. Path. Jap. 46 ; 240.21 ) Burstone, M. S. (1958) : J. Natl. Cancer Inst. 21 ; $539 . \quad 22)$ Burstone, M. S. and Weisburger, E. K. (1961) : J. Histochem. Cytochem. 9; 301 . 23) Holt, S. J, (1959) : Exp. Cell Res. Suppl. 7 ; 1 . 24) Gomori, G. (955) : J. Histochem. 3 ; 479 . 25) Burstone, M. S. (1959) : J. Histochem. Cytochem. 7 ; 112 . 26) Burstone, M. S. (1960) : J. Histochem. Cytochem. $8 ; 63$.

\title{
Artifacts in Frozen Sections
}

\author{
Morio InNuma \\ Department of Anatomy, Tokyo Women's Medical College, Shinjukuku, Tokyo.
}

In histochemical studies cryostat sections are commonly used, but one must give attention to the fact that many histological and histochemical artifacts can be made during manipulation of cryostat sections. In this paper artifacts of stained cryostat sections are clarified and improved method to minimize these artefacts is shown.

Pieces of rat liver were rapidly frozen in isopentane chilled with mixture of dry ice and acetone. Then the frozen material is cut into 8 micron sections with sliding microtome in a Coons-type cryostat maintained at $-15^{\circ} \mathrm{C}$. The histological appearance of sections prepared by the method of Coons et al. can not be said good one. When periodic acid-Schiff stain is applied to these sections, strong PAS positivity is observed in sinusoid not in hepatic cells (Fig. 1). The same distribution of PAS positive substances is observed in the sections dried by the method of Coons et al. and stained by PAS procedure after $95 \%$ ethanol fixation. These facts show that glycogen has flowed into sinusoid from hapatic cells before staining procedure. This flowing of glycogen from hepatic cells may be caused by dewing on the cold slide glass when it is brought out from cryostat into warm atmosphere. So it is easily suggested that any improvement in preventing the flowing of glycogen from 